\title{
A comparison of simple tests to distinguish cerebrospinal fluid from saline
}

Dean S Walker MD, *

John G Brock-Utne MD PhD ${ }^{\dagger}$

Purpose: This prospective study was undertaken to determine if anesthesiologists of different levels of training, using simple tests, can distinguish cerebrospinal fluid (CSF) from saline.

Methods: Thirty-two anaesthetists, divided into four groups, dependent upon levels of training, participated in the study. Each was asked to distinguish saline from an artificial CSF solution using four different tests: tactile temperature, glucose strip. pH strip, and turbidity when mixed with thiopental.

Results: Participants identified cerebrospinal fluid correctly with $84 \%$ accuracy using the temperature test, $97 \%$ using the glucose test, $91 \%$ using the $\mathrm{pH}$ test, and $50 \%$ using the thiopentone test. More than half of the participants guessed while using the thiopentone test, and those who did not guess were only $47 \%$ accurate.

Conclusion: Level of training made no difference in distinguishing CSF from saline. No one test was $100 \%$ reliable. Clinical utility of the thiopentone test appears to be limited. The temperature, glucose, and pH tests, when used together, appear to be a useful way of distinguishing CSF from saline.

Objectif : Cette étude prospective visait à déterminer si des anesthésistes possédant des degrés différents de formation pouvaient, à laide de simples tests, faire la distinction entre du liquide céphalo-rachidien (LCR) et du sol.phys (SP).

Méthodes : Trente-deux anesthésistes, divisés en quatre groupes d"après leur niveau de formation, ont participé à l'étude. On a demandé a chacun de faire la distinction entre du SP et une solution artificielle de LCR en utilisant quatre tests différents : la température tactile, le papier réactif au glucose. le papier réactif au pH et l'épreuve de turbidité au thiopentone.

Résultats : les participants ont identifié correctement le LCR avec un degré d'exactitude de $84 \%$ avec le test de la température. $97 \%$ avec le test du glucose. $91 \%$ avec le test $\mathrm{du} \mathrm{pH}$ et $50 \%$ avec le test de turbidité au thiopentone. Plus de la moitié des participants ont «deviné» avec le test au thiopentone et l'exactitude riétait que de $47 \%$ chez ceux qui n'avaient pas deviné.

Conclusion : Le niveau de formation nia fait aucune difference lorsqu'il s'agissait de distinguer entre le LCR et le soluté physiologique. Aucun des tests riétait fiable à $100 \%$. Les tests de la température, du glucose et du pH, utilisés conjointement, semblent utiles pour distinguer le liquide céphalo-rachidien du soluté physiologique.

From the Department of Anesthesia, Stanford University Medical Center, Stanford, CA 94305-5115.

Address correspondence to: Dr. John G. Brock-Utne.

Phone: 415-723-6411; Fax: 415-725-8544; E-mail: Brockutn@Leland.Stanford.edu Accepted for publication 9 February 1997. 
A

SALINE-FILLED syringe is frequently used to help identify the epidural space prior to placement of an epidural catheter, using the "loss of resistance" technique. Saline can also be used to expand the epidural space before insertion of the epidural catheter. Unfortunately, fluid may be aspirated from the catheter before injection of the local anaesthetic solution. If saline was used during identification or expansion of the epidural space, this fluid may be saline but could also be cerebrospinal fluid. The anaesthetist must be able to distinguish between these two fluids.

Four methods of identifying fluid as saline or CSF have been described: temperature, ${ }^{1}$ presence of glucose, ${ }^{1-3} \mathrm{pH}^{4}$ and turbidity when mixed with thiopentone. ${ }^{5}$ Tessler et al. found that these four tests, when used together, were useful in distinguishing cerebrospinal fluid from local anaesthetic solution in vitro. ${ }^{6}$ We sought to determine if the level of training of the anaesthetist would make a difference in distinguishing cerebrospinal fluid from saline.

\section{Materials and methods}

Thirty-two anaesthetists participated in the study. Each was assigned to one of four groups, based on level of training and frequency of epidural catheter placement. These groups included: residents in their second or third year of training, ${ }^{10}$ anaesthesia fellows who had completed a residency programme in the last one to three years, ${ }^{5}$ board-certified anesthesiologists who placed epidural catheters infrequently (less than three times per week, on average), ${ }^{11}$ and board-certified anesthesiologists who placed epidural catheters frequently. ${ }^{6}$

Each anaesthetist was asked to distinguish a sample of plain saline from a sample of mock CSF solution. The participants were unaware of the identity of the two samples to be examined. The CSF solution was made of saline, warmed to $37^{\circ} \mathrm{C} \pm 0.5^{\circ} \mathrm{C}$ with glucose $0.5 \mathrm{~g} \cdot \mathrm{L}^{-1}$ added, $\mathrm{pH}$ adjusted to 7.4. All tests were done at Stanford University Medical Center. The anaesthetist performed four tests on both samples:

\section{Temperature}

A samples, $0.1 \mathrm{ml}$, of CSF solution or plain saline at room temperature $\left(22^{\circ} \mathrm{C} \pm 1^{\circ} \mathrm{C}\right)$ was dropped on the subject's skin from approximately three centimeters. The site chosen was either the dorsal aspect of the hand or the volar aspect of the forearm, at the subject's discretion, based on the method he/she would normally use clinically. As a standardizing measure, the warmed solution was applied first. The subject was asked to identify both solutions based on temperature alone. Participants were not advised as to which solution should feel warmer.

\section{Presence of glucose}

A sample, $0.1 \mathrm{ml}$, of CSF solution or plain saline was placed onto separate urine glucose test strips (Ames ${ }^{\circledR}$ Bili-Labstix ${ }^{\otimes}$ Reagent Strips for Urinalysis, by Miles, Inc). The examiners were shown the strips simultaneously, immediately after application of both solutions. They were asked to identify the solutions after $60 \mathrm{sec}$ based on the colour of the strips. The subjects were not advised as to which solution should test positive for glucose.

\section{$p H$}

A sample, $0.1 \mathrm{ml}$, of CSF solution or plain saline was placed onto separate urine $\mathrm{pH}$ test strips $\left(\right.$ Ames $^{\circledR}$ BiliLabstix ${ }^{\circledast}$ Reagent Strips for Urinalysis, by Miles, Inc.). These strips were separate from the aforementioned glucose test strips. The examiners were shown the strips simultaneously and were asked to identify the solutions based on the colour of the strips after $60 \mathrm{sec}$. The subjects were not advised as to which solution should have the higher $\mathrm{pH}$.

\section{Turbidity when mixed with sodium thiopentone}

A sample of CSF solution or plain saline was mixed with an equal volume of thiopentone $2.5 \%$ on separate glass slides. The examiners were to identify the solutions based on turbidity seen on the slides. All subjects were advised before beginning the test that thiopentone becomes more turbid when mixed with solutions of low $\mathrm{pH}$.

\section{Results}

\section{Temperature}

The majority, $84 \%$, of participants identified cerebrospinal fluid correctly by tactile temperature sensation. Residents were correct with $90 \%$ accuracy, fellows $60 \%$, attendings who place epidurals infrequently $91 \%$, and attendings who frequently place epidurals $83 \%$ (Figure 1).

\section{Presence of glucose}

Almost all, 97\%, participants identified cerebrospinal fluid correctly using a glucose test strip. Residents, fellows, and attendings who place epidurals frequently 
were correct $100 \%$ of the time. Attendings who place epidurals infrequently were $91 \%$ accurate (Figure 2).

\section{$p H$}

Most, $91 \%$, participants identified cerebrospinal fluid correctly using a pH test strip. Residents and attendings who place epidurals infrequently were correct $100 \%$ of the time. Fellows were $60 \%$ accurate, and attendings who place epidurals frequently were $83 \%$ accurate (Figure 3 ).

\section{Turbidity when mixed with thiopentone}

Half of the participants identified cerebrospinal fluid correctly using the thiopentone test. Residents were correct with $50 \%$ accuracy, fellows $60 \%$, attendings who place epidurals infrequently $36 \%$, and attendings who frequently place epidurals $60 \%$. Fifty three percent of participants were unsure and guessed. Of the remaining $47 \%$ who did not guess, only $47 \%$ were correct (Figure 4).

\section{Discussion}

When using the "loss of resistance" technique for identification of the epidural space, a saline-filled syringe has clear advantages over an air-filled syringe. The risks of air embolism and neurological deficit are potentially reduced, and there are no air pockets left in the epidural space that, potentially, may inhibit the spread and effectiveness of local anaesthetics. ${ }^{\text {? }}$

Dilating the epidural space prior to placement of an epidural catheter is safer when saline is used rather than local anaesthetic solution. The consequences of inadvertent intravascular or intrathecal injection are trivial when using saline, so the Tuohy needle does not need to be tested before threading the catheter.

However, it may be more difficult to detect inadvertent dural puncture when saline is used rather than air or local anaesthetic solution. When using an airfilled syringe to find the epidural space, the subsequent presence of fluid in the syringe is highly suggestive of dural puncture. This clinical observation is not possible with a saline-filled syringe. Also, as saline has a higher $\mathrm{pH}(6.5)$ than local anaesthetic solution (5.0), $\mathrm{pH}$-sensitive tests may be more difficult to perform in distinguishing CSF from saline than when distinguishing CSF from local anaesthetic solution. ${ }^{4,5}$

In our study, the level of training had no bearing on the success of distinguishing CSF from local anaesthetic solution. We conclude with Tessler et al. ${ }^{6}$ that no one test was $100 \%$ sensitive. Surprisingly, the temperature test had only an $84 \%$ sensitivity. This is simi-
Temperature Test

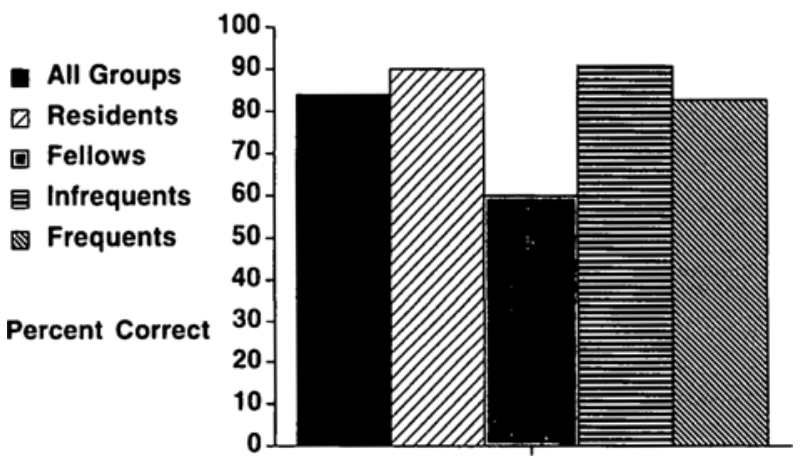

FIGURE 1 Accuracy (\%) in distinguishing CSF from saline, using a tactile temperature test.

\section{Glucose Test}

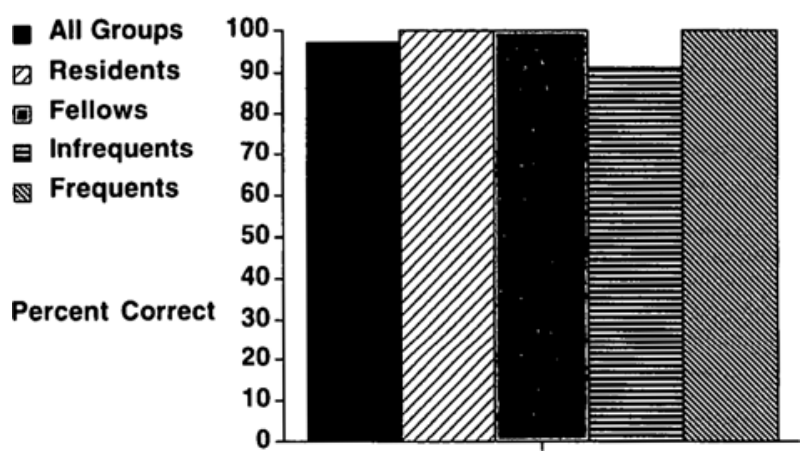

FIGURE 2 Accuracy (\%) in distinguishing CSF from saline, using a glucose test strip.

pH Test

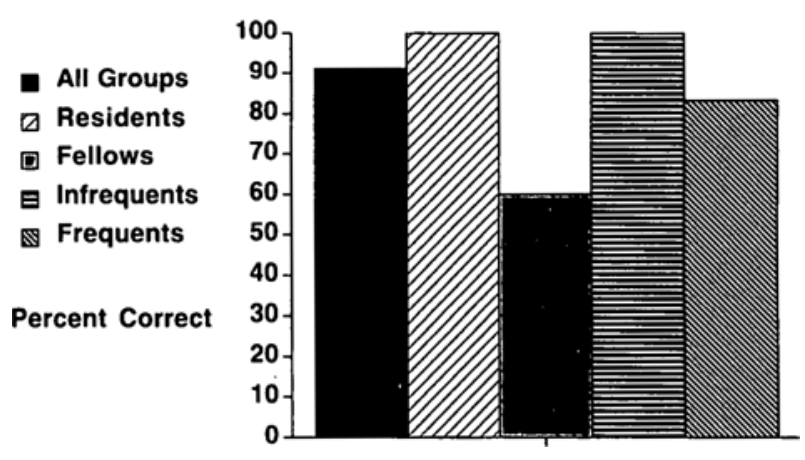

FIGURE 3 Accuracy (\%) in distinguishing CSF from saline, using a $\mathrm{pH}$ test strip. 


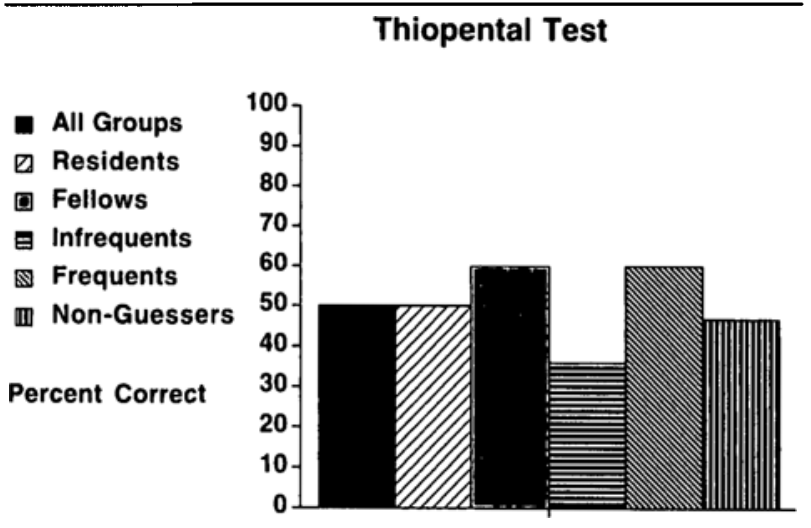

FIGURE 4 Accuracy (\%) in distinguishing CSF from saline, using a thiopentone turbidity test.

lar to Tessler's findings (75\%), however, results may be even less reliable in clinical practice. Saline injected into the epidural space can potentially be warmed by the patient, hence the fluid temperature may be somewhere between that of the room and of the body. Also, different fluids at room and body temperatures are generally not available to a clinician, as they were in this study.

The glucose and $\mathrm{pH}$ tests were both highly sensitive, $97 \%$ and $91 \%$ respectively (Tessler, $92 \%$ and $83 \%$ respectively). Urine dip sticks are inexpensive, and they often have glucose and $\mathrm{pH}$ indicators on the same strip. These tests are not affected by fluid temperature, and appear to be the most reliable tests of those studied.

The clinical utility of the thiopentone test appears to be limited, which is similar to Tessler's results $(25 \%)$. While all participants were briefed as to how acidic solutions were proposed to react with thiopentone, answers appear to have been arbitrary, even among those who were not guessing. This may be because saline is less acidic than local anaesthetic solution and is, thereby, less likely to produce reaction with thiopentone than is local anaesthetic solution.

In summary, the level of training had no effect on the success of distinguishing CSF from saline. Our study concurs with Tessler $e t$ al. that glucose and $\mathrm{pH}$ test strips are sensitive in distinguishing cerebrospinal fluid from saline. Tactile temperature testing may be more accurate when air is used in the loss of Tuohy resistance technique. The thiopentone test is considered not to be useful.

\section{References}

1 Berry A. Test for spinal fluid (Letter) Anaesthesia 1958; 13: 100-1.

2 Gavin $R$. Continuous epidural analgesia. An unusual cause of dural perforation during catheterisation of the epidural space. N Z Med J 1965; 64: 280-1.

3 Waters JH, Ramanatban S, Chuba JV. Glucose in epidural catheter aspirate. Anesth Analg 1993; 76: 546-8.

4 Reisner LS. Epidural test solution or spinal fluid? (Letter) Anesthesiology 1976; 44: 451.

5 Catterberg J. Local anesthetic vs. spinal fluid (Letter). Anesthesiology 1977; 46: 309.

6 Tessler MJ, Wiesel S, Wabba RM, Quance DR. A comparison of simple identification tests to distinguish cerebrospinal fluid from local anaesthetic solution. Anaesthesia 1994; 49: 821-2.

7 Rolbin SH, Halpern SH, Braude BM, Kapala D, Unger $R$, Radhakrisnan $S$. Fluid through the epidural needle does not reduce complications of epidural catheter insertion. Can J Anaesth 1990; 37: 339-40. 